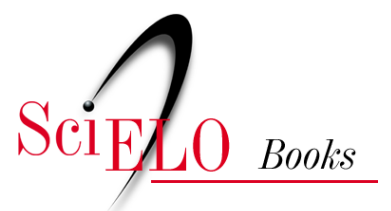

\title{
10. A Abrasco na Construção de uma Agenda Internacional em Saúde
}

\author{
Alvaro Hideyoshi Matida \\ Paulo Buss
}

\section{SciELO Books / SciELO Livros / SciELO Libros}

MATIDA, A.H., and BUSS, P. A Abrasco na Construção de uma Agenda Internacional em Saúde. In: LIMA, N.T., SANTANA, J.P., and PAIVA, C.H.A., orgs. Saúde coletiva: a Abrasco em 35 anos de história [online]. Rio de Janeiro: editora FIOCRUZ, 2015, pp. 215-227. ISBN: 978-85-7541-590-0. Available from: doi: $10.7476 / 9788575415900.0012$. Also available in ePUB from: http://books.scielo.org/id/q4gzb/epub/lima-9788575415900.epub.

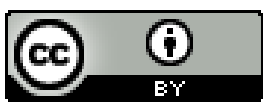

All the contents of this work, except where otherwise noted, is licensed under a Creative Commons Attribution 4.0 International license.

Todo o conteúdo deste trabalho, exceto quando houver ressalva, é publicado sob a licença Creative Commons Atribição 4.0. 


\title{
A Abrasco na Construção de \\ uma Agenda Internacional em Saúde
}

Alvaro Hideyoshi Matida

Paulo Buss

\begin{abstract}
A partir de sua criação, em 1979, e ao longo desses 35 anos, a historia da Associação Brasileira Saúde Coletiva (Abrasco) se mescla a duas necessidades da saúde coletiva brasileira: seguir integrando o assim chamado movimento de Reforma Sanitária brasileira e o processo de debate em torno da evolução das políticas e das práticas da saúde pública; e discutir, redefinir e participar do processo de formação de pessoal para o campo da saúde, visando ao cumprimento de uma agenda de mudanças e de reforço aos valores e princípios orientadores da saúde coletiva. Essa última vertente, voltada para a redefinição da formação profissional em saúde, também é parte integrante do movimento de Reforma Sanitária nos anos 1980.

Um marco referencial desse movimento a que a Abrasco se integrou foi o fomento ao processo de organização da $8^{a}$ Conferência Nacional de Saúde (CNS) (1986) e seus desdobramentos, em particular a discussão em torno da Constituição Brasileira (1988). A comissão organizadora da 8 a CNS, presidida por Sergio Arouca, foi bastante atuantena discussão do temário ao longo desse processo organizativo. O temário foi constituído pelos seguintes itens: saúde como direito, reformulação do sistema nacional de saúde e financiamento da saúde.

O reconhecimento nacional da Abrasco no processo político e técnico nacional projetou-a em nível continental e internacional. Atraindo a atenção de outras associações equivalentes, os primeiros anos do século XXI, atéo presente, foram particularmente relevantes para a internacionalização das ações da associação. Entre elas, a mais importante talvez tenha sido a conquista do direito de realizar no Brasil, em 2006, o Congresso Mundial de Saúde Pública, da Federação Mundial de Associações de Saúde Pública (World Federation of Public Health Associations - WFPHA). Em 2004 e 2005, em conjunto com a WFPHA, a instituição
\end{abstract}


organizou e promoveu esse evento internacional que reuniu cerca de 12 mil profissionais, dos quais aproximadamente mil eram estrangeiros de diversos países.

Esse e outros eventos e participações da Abrasco - que ajudaram a construir sua face internacional - serão discutidos neste capítulo, procurando fazer uma abordagem em três dimensões: saúde global e diplomacia da saúde; os 35 anos da Abrasco e a construção de uma agenda internacional; e os desafios da instituição no campo internacional nos anos próximos.

\section{Saúde Global e Diplomacia da Saúde}

O "breve" século XX, como definido por Eric Hobsbawm (1994), foi marcado por importantes avançoseconômicos, sociais etécnico-científicos, os quais melhorarama qualidade de vida eas condições de saúdeem todo o mundo. Contudo, como"era dos extremos", na mesma definição de Hobsbawm, o processo de globalização também tem criado grandes disparidades, produzindoenormes problemassociaisedesaúde, particularmentenos paísesmaisexcluídosdos circuitos centrais da economia global. As condições declinantes da saúde de grandes parcelas da população, a insegurança alimentar e, evidentemente, as mudanças climáticas vêm sendo motivo de preocupações da chamada comunidade internacional.

Quandoenunciamossaúdeglobal,estamosnos referindoaproblemasquetranscendem asfronteiras dos Estados-nacionaise quenãosão passíveis desoluçãoapenas pelas diplomacias dos países, o que seria objeto da saúde internacional, no sentido de negociações entre nações.

Com diversas iniciativas, atendendo a interesses muitas vezes contraditórios, as Nações Unidas, a cooperação sul-sul (entre países em desenvolvimento), as agências de cooperação de países desenvolvidose dealguns países emergentes, assim comoafilantropia internacional, têm colocado a saúde como prioridade na agenda da cooperação internacional e dos programas de ajuda para o desenvolvimento. Esse processo tem sido denominado diplomacia global da saúde, ou seja, o conjunto de negociações desenvolvidas em diversos níveis, que delineia e gerencia o ambiente das políticas globais em saúde - e que, idealmente, produz melhores resultados para a saúde da população de cada país envolvido (atendendo, assim, aos interesses nacionais), bem como implementa as relações entre Estados e reforça o compromisso de um amplo arco de atores em prol do empreendimento comum de assegurar a saúde como direito humano e bem público (Kickbusch, Silberschmidt \& Buss, 2007). Como exemplo, pode-se mencionar os Objetivos de Desenvolvimento do Milênio, conjunto de compromissos definidos pela Cúpula do Milênio, realizada pelas Nações Unidas no ano 2000 (ONU, 2000). E, mais recentemente, o processo de definição da Agenda do Desenvolvimento pós-2015 (ONU, 2013) e os Objetivos do Desenvolvimento Sustentável (ONU, 2014), entre os quais se encontra a saúde.

Iniciativas de diplomacia da saúde podem ser identificadas no interior da governança da saúde global, e é natural que assim seja. Entende-se como tal"o uso de instituições, regras e processos formais ou informais por parte de Estados, instituições intergovernamentais 
e agentes não estatais para lidar com desafios de saúde que demandem ações coletivas e transfronteiriças de forma efetiva" (Fidler, 2010: 2). A Organização Mundial da Saúde (OMS) é a instituição que lidera o processo da saúde global, embora cada vez mais seu papel seja questionado e ela se veja forçada a compartilhar sua liderança com um conjunto de novos atores globais. Os Estados-membros da OMS praticam permanentemente a diplomacia da saúde entre si no âmbito da organização.

Entretanto, o que se verifica mais recentemente éa importância crescente que decisões externas ao setor têm sobre a saúde global - assim como, por extensão, as políticas nacionais de saúde. O que se denomina de governança global é um

conjunto de instituições, mecanismos, relações e processos complexos formais ou informais entreEstados, mercados, cidadãos eorganizações intergovernamentais ou não governamentais, por meio dos quais, em nível global, interesses coletivos são articulados, leis e obrigações são estabelecidas, e diferenças são mediadas. (Thakur \& Weiss, 2006: 6)

Quando nos referimos à governança, estamos incluindo não só governos, mas também a sociedade civil (Buss, 2012).

A Associação Canadense de Saúde Pública (Canadian Public Health Association CPHA) lançou, em 1985, o Strengthening of Public Health Associations Program (Sopha) - Fortalecendo as Associações de Saúde Pública - como uma de suas mais importantes iniciativas de saúde global, reflexo de seus valores e princípios internacionais (CPHA, 1985). O Sopha provê apoio técnico e financeiro visando a fortalecer associações de saúde pública em trinta países em desenvolvimento a fim de garantir a defesa da saúde e a promoção de ampla participação pública em questões e ações sanitárias. Em nosso entendimento, esse é um dos melhores exemplos de governança da saúde global desenvolvida, nesse caso, não entre países, mas entre organizações não governamentais (ONGs) - as associações nacionais de saúde pública - por uma associação nacional.

A agenda internacional da Abrasco pode-se inscrever nesse conceito amplo de governança global e saúde e, se apropriadamente desenvolvida, contribuir enormemente para o avanço da saúde e da própria disciplina global e regionalmente.

\section{Os 35 Anos da Abrasco e a Construção de uma Agenda Internacional}

Nesses 35 anos de existência, a Abrasco vem servindo para intercâmbio e construção de conceitos e valores em saúde pública/coletiva, troca de informações científicas e divulgação de congressos e eventos da própria associação e de outras organizações nacionais e internacionais. Nessa perspectiva, os congressos brasileiros de saúde coletiva, bem como os eventos temáticos das comissões e grupos temáticos (GTs) da Abrasco, seus desdobramentos, declarações eagendas produzidas tiveram registro e expressão em anais de eventos, boletins informativos, documentos e relatórios. 
De fato, mescladas à construção de uma agenda internacional da saúde, o processo de revisita a conceitos e valores que fomentaram o debate em torno do movimento da Reforma Sanitária brasileira e seus desdobramentos sublinharam a trajetória da Abrasco. O $1^{\circ}$ Congresso Brasileiro de Saúde Coletiva, em setembro de 1986, na Universidade do Estado do Rio de Janeiro (Uerj), na cidade do Rio de Janeiro, teve como tema "Reforma Sanitária e Constituinte: garantia do direito universal à saúde". Os grandes conceitos, valores, teses e políticas relativos à saúde como direito universal e dever do Estado, a regionalização, a integralidade do cuidado à saúde - entre outros temas discutidos e defendidos nesseevento histórico pelo conjunto dos participantes, lideranças, cientistas e pesquisadores, quer no âmbito das academias, quer no âmbito dos serviços de saúde - foram aqueles advogadas pelo movimento sanitário ao longo do processo de organização da $8^{a}$ Conferência Nacional de Saúde e que estão plasmados na Constituição Brasileira. A Declaração do Rio de Janeiro, resultado desse primeiro congresso, expõe:

A ABRAsco se alia a todos aqueles que almejam a democratização da saúde e acredita que só através da nossa organização coletiva alcançaremos legitimar as medidas que avançam na direção da Reforma Sanitária e impedir, com a nossa vigilância constante, qualquer retrocesso no curso desse processo.

Nesse sentido, reafirmamos:

- a necessidade da continuidade no processo de mobilização social em torno da Reforma, iniciado com a $8^{\text {a }}$ CNS;

- o apoio à Comissão Nacional da Reforma Sanitária para que esta se legitime e ganhe força, para propor as transformações que se fazem necessárias;

- (...) e o nosso engajamento decisivo no processo constitucional, estabelecendo um projeto para a área de saúde a ser inscrito na Nova Constituição e comprometendo desde agora os candidatos com as propostas da Reforma Sanitária. (...) Nesse sentido, recomendamos que sejam organizados fóruns de debate e mobilização em todos os cantos do país, articulando, assim, as representações dos trabalhadores, comunidade, instituições, partidos políticos, universidades etc., a nível local, municipal e estadual. Desta forma, concretizaremos ainda mais a discussão sobrea ReformaSanitária, conquistando onecessário respaldo organizativo da sociedade para a sua definitiva implantação (Plenária do $1{ }^{\circ}$ Congresso Brasileiro de Saúde Coletiva). (Cadernos de Saúde Pública, 1986: 383-384)

Em novembro de 1988, divulga-se o $2^{\circ}$ Congresso Brasileiro de Saúde Coletiva "Sistema Único de Saúde: conquista da sociedade" -, que ocorreria na Universidade de São Paulo (USP), de 3 a 7 de julho de 1989. "O período não pode ser mais propício, pois estará iniciando a legislatura de 1989, e a lei orgânica sobre a saúde, regulamentando os princípios constitucionais, deverá ser votada no próximo ano no Congresso Nacional" (Abrasco, 1988: 1). A Carta de São Paulo, aprovada na sessão plenária no fim do $2{ }^{\circ}$ Congresso, explicita a ausência de locação de recursos e investimentos no setor Saúde pelo governo Sarney e relaciona as exigências para a manutenção e o avanço do projeto de Reforma Sanitária (Abrasco, 1989: 5). 
O editorial do Boletim Abrasco n. 46, ao tempo que promove as cartas de Porto Alegre e Belo Horizonte - resultantes do $3^{\circ}$ Congresso Brasileiro de Saúde Coletiva, em Porto Alegre (RS), em maio de 1992, e do $2^{\circ}$ Congresso Brasileiro de Epidemiologia, em Belo Horizonte (MG), em julho desse mesmo ano, ambos realizados pela associação -, divulga a 9a Conferência Nacional de Saúde, cujo tema "Municipalização é o caminho" reitera a regionalização do sistema de saúde brasileiro e a regulamentação da Constituição de 1988.

Nesse mesmo boletim, a Abrasco torna públicos à comunidade da área de saúde três eventos internacionais a serem realizados em outubro de 1992: a 7a Conferência da Associação Internacional de Políticas de Saúde, em Bolonha (Itália), com o objetivo de promover a análise de questões ligadas à saúde pública e dinamizar o debate entre países sobre políticas de saúde; e a 7a Jornada de Saúde e Administração Sanitária e o $1^{\circ}$ Congresso Ibero-Americano de Epidemiologia, em Granada (Espanha), visando a debater problemase definir linhas de investigação em epidemiologia dos países participantes (Abrasco, 1992b).

O que há por fazer depois do já feito - ou "Saúde: o feito por fazer", tema geral do $4^{\circ}$ Congresso Brasileiro de Saúde Coletiva, no Centro de Convenções de Olinda e Recife (Pernambuco), em junho de 1994 - é objeto de ampla divulgação no Boletim Abrasco n. 51.

Desejando a construção coletiva do Congresso, ampliando o compromisso das instituições e entidades para com a área e adscrevendo-Ihes responsabilidades no processo, a Diretoria tem estadodialogandopermanentementecomacomunidade, recebendoeavaliandosugestõessobre o temário e organização do evento (...). Éconsensual a importância do Congresso montado sobre eixos temáticos que permitam a discussão do arcabouço legal do Sistema Único de Saúde, a revisão do atual modelo assistencial e o desenho de estratégias para a consolidação do processo de implementação do SUS. (Abrasco, 1993: 1)

No fim de julho de 2003, em Brasília, durante o $7^{\circ}$ Congresso Brasileiro de Saúde Coletiva ("Saúde, justiça, cidadania"), realizou-se uma Oficina de Integração Regional do Setor Saúde na América do Sul, promovida pelo Ministério da Saúde, em torno do fortalecimento dos sistemas de inovação em saúde e da cooperação solidária entre países do bloco (Abrasco, 2003).

Assim é que no início dos anos 2000, no editorial do Boletim Abrasco n. 90, o então presidente da associação, professor Moisés Goldbaum, expressa que

no cenário internacional, vale sublinhar o empenho da diretoria junto à Federação Mundial de Associações de Saúde Pública (WFPHA) visando à realização da $11^{\text {a }}$ edição do Congresso Mundial de Saúde Pública, na cidade do Rio de Janeiro. A proposta enviada e aprovada, por unanimidade, no plenário da 38 Reunião Anual da WFPHA em 19 de abril de 2004, cuja organização será articulada com o próximo Congresso Brasileiro de Saúde Coletiva. É nossa expectativa seguirmos ampliando, fortalecendo o debate eo intercâmbio de ideias eações entre a comunidade científica nacional e internacional. (Abrasco, 2004: 2-3)

A aproximação da Abrasco com os temas da saúde global, assim como sua interação com as atividades da WFPHA, consolida a necessária ampliação da sua agenda internacional 
e resulta no seu reconhecimento perante a comunidade internacional. O $8^{\circ}$ Congresso Brasileiro de Saúde Coletiva e o 11 Congresso Mundial de Saúde Pública ("Saúde coletiva em um mundo globalizado: rompendo barreiras sociais, econômicas e políticas"), realizados no Rio de Janeiro de 21 a 25 de agosto de 2006, evidenciam essa tese.

A realização de um fórum mundial, no Brasil, é extremamente oportuna e merece toda nossa credibilidade. À frente desta iniciativa, a Associação Brasileira de Pós-Graduação em Saúde Coletiva/Abrasco eaWFPHA prestarão grande tributo ao desenvolvimento do campo no âmbito internacional. A ampliação do debate e a formulação de propostas inovadoras em Saúde Pública Internacional são, hoje, mais que nunca, uma urgência e um imperativo ético (trecho da carta do dr. Humberto Costa, ministro de Estado de Saúde, dirigida à WFPHA). (Abrasco, 2006a: 3)

Em seiscentas horas de atividades, estiveram presentes delegações de 77 países, 12 mil participantes, nacionais e internacionais, profissionais da saúde, lideranças, tomadores de decisão, professores, pesquisadores, além da presença marcante do então presidente da República, Luiz Inácio Lula da Silva. A programação do $11^{\circ}$ Congresso Mundial de Saúde Pública contou com a presença do presidente da Fundação Oswaldo Cruz (Fiocruz), Paulo Buss, homenageado pelaWFPHA e convidado a proferir a Conferência Magna Hugh Rodman Leavell, intitulada"Globalização, pobreza e saúde", abordando o impacto das políticas econômicas sobre as iniquidades sociais, pobreza e saúde. As apresentações de Michael Marmot ("Ações globais em determinantes sociais em saúde") e Giovani Berlinguer ("Novas fronteiras em ciência e tecnologia: o que isso significa para a saúde pública?"), juntamente com as contribuições de ministros daSaúde, delegadoserepresentantesinstitucionais de países, resultaramnaaprovação da Declaração do Rio de Janeiro na sessão plenária de encerramento, na qual se reafirmou que:

- Oacesso ao cuidado de saúde eficazé um direito humano fundamental e uma pré-condição para o desenvolvimento social e econômico; (...)

- Os resultados da pesquisa devem estar publicamente disponíveis e ser incorporados na formulação de políticas públicas e intervenções em saúde (...);

- São necessários laços intersetoriais mais fortes entreas políticas públicas em geral eas de saúde, eligações efetivas com iniciativas governamentais, não governamentais eda sociedade civil;(...)

- As agências das Nações Unidas devem ter os meios necessários e se comprometerem com ações melhores e mais ágeis;

- A solidariedade e responsabilidade globais são essenciais para que se faça frente ao enorme desafio de garantir que todo ser humano possa viver sua vida com respeito e dignidade, criando, desta forma, um futuro melhor para as próximas gerações. (Abrasco, 2006c: 5)

Em entrevista publicada no Boletim Abrasco n. 97, o então presidente da instituição, professor Paulo Gadelha, detalha as principais repercussões do congresso, que pela primeira vez teve a participação do presidente da República. Faz um balanço do movimento da Reforma Sanitária e do futuro do Fórum da Reforma Sanitária e "se diz confortável para passar o bastão ao companheiro" José da Rocha Carvalheiro, presidente da entidade na gestão 2007-2009 (Abrasco, 2006b: 10). 
Nesse congresso, alcançamos um patamar de consolidação da Abrasco como referência nacional e internacional e também tivemos um momento muito especial para trazer à tona a politização da saúde pública. (...)

Ela [a Abrasco] revisitou as questões que galvanizaram o movimento de Reforma Sanitária. Conseguiu perceber a predominância das questões mais gerais técnicas, políticas eacadêmicas e as traduziu numa forma de pertinência e linguagem que capturou e interessou segmentos muito diversificados.

Houve avanço na construção institucionalizada e organizada da participação, que resultou nos conselhos, nas conferências e seu crescimento em número de participantes, temáticas e novas plenárias.

A ideia de começar a reconstituir o Fórum de Saúde, com a reunião inicial de entidades (Abrasco, Cebes, Rede Unida, Associação Brasileira de Economia da Saúde (Abres), Associação Nacional do Ministério Público de Defesa da Saúde (Ampasa), o fortalecimento da rede parlamentar, da articulação mais orgânica com o Conselho Nacional de Saúde, a "refundação do Cebes" - braço muito importante do processo de repolitização - e a própria concepção do Congresso da Abrasco refletem um movimento de busca de uma significação mais ampla para o Fórum. Eu acho que os desafios são muito grandes, principalmente em um processo eleitoral no país fracamente politizado, no qual questões centrais, como a saúde e o futuro da nação, ficam relegadas. (Abrasco, 2006b: 11-12)

A construção dessa agenda internacional da Abrasco segue o $4^{\circ}$ Congresso Brasileiro de Ciências Sociais e Humanas em Saúde, realizado em Salvador no período de 13 a 18 de julho de 2007. Em conjunto com a Associação Latino-Americana de Medicina Social (Alames) e a Associação Internacional de Políticas de Saúde (IAHP), a Abrasco coorganizou esse triplo congresso com o tema "Equidade, ética e direito à saúde: desafios à saúde coletiva na mundialização", dividido em quatro eixos temáticos: Saúde Coletiva Hoje; Equidade e Direito à Saúde; Direito à Vida e à Paz; Mobilização e Participação Social. As trocas de experiências e as discussões entre participantes, por um lado, demonstram a complexidade do campo da saúde coletiva em face da necessidade de ações intersetoriais estruturantes, da precariedade de investimentos e dos modelos de governança adotados; por outro, indicam a urgência de um novo contrato social e incursões criativas e alternativas aos modelos e paradigmas em foco. Em entrevistas com representantes tanto da Alames quanto da IAHP, que juntamente com a Abrasco realizaram esse evento internacional, tal posicionamento é reiterado e somado a questões relativas aos direitos humanos e à mobilização social global (Abrasco, 2007).

Oprotagonismo da Abrasco no processo de elaboração da Declaração do Rio de Janeiro, em 2006, e da Declaração de Istambul, em 2009; e sua participação na presidência da WFPHA entre 2007 e 2008, integrando assessorias e GTs desde 2006 até o presente momento, são fatos bastante relevantes. Em conjunto com outras entidades civis e a WFPHA, a Abrasco esteve presente na Conferência Mundial de Determinantes Sociais da Saúde organizada pela OMS, no Rio de Janeiro, em outubro de 2011; e organizou e participou dos dois Encontros Latino-Americano de Entidades de Saúde Pública, ambos em Porto Alegre em 2011 e 2013, que tiveram como objetivo buscar estratégias para a definição e consolidação de uma 
rede de organizações latino-americanas para fortalecer agendas nacionais das entidades participantes (encontros e fóruns relevantes) e construir uma agenda comum de interação latino-americana em saúde coletiva.

Ainda no processo de construção de uma agenda internacional, a instituição elege em setembro de 2006, em Assembleia Geral da Federação, durante a realização do $11^{\circ}$ Congresso da WFPHA e do $8^{\circ}$ Congresso da Abrasco, Paulo Buss - ex-secretário da associação e, na época, presidente da Fiocruz - para a presidência da Federação Mundial de Associações de Saúde Pública. A posse do novo presidente ocorre por ocasião da Assembleia da Federação, em Genebra, em maio de 2008.

Centenas de países e bilhões de pessoas enfrentam todos os dias o absurdo da fome, as habitações insalubres, a ameaça de doenças, a falta de liberdade, as guerras sem sentido, a violência e a falta de acesso a serviços sociais básicos. Todos estes fenômenos - e muitos outros - influenciam negativamente a saúde de cada um e da coletividade.

Nós, profissionais de saúde pública, não podemos aceitar que as iniquidades sejam ainda a tônica da vida política, social e econômica na maioria dos países do mundo. Sabemos o quanto as desigualdades socialmente injustas e inaceitáveis são a verdadeira raiz da maioria dos problemas sociais e de saúde que afetam nossas populações. (...)

Quando examinamos os fundamentos políticos e técnicos desta Federação nos damos conta do imenso patrimônio amealhado ao longo dos seus quarenta anos de vida, desde que foi fundada em 1967.Éaúnica associação profissional global representando e servindo a saúde pública como um todo, ao invés de disciplinas separadas ou profissões. Desde 1978, como uma organização da sociedade civil internacional, não governamental e multiprofissional, esta Federação une todas as pessoas interessadas e ativas em salvaguardar e promover a saúde da população através da troca profissional, colaboração e ação. (...)

O mundo contemporâneo está cada vez mais complexo, desafiando instituições como a nossa, e múltiplos atores atuam na cena internacional, o que exige atuação em parcerias, com a construção de consensos políticos para a ação. (...)

Encerro estas palavras convocando a todos para uma luta sem tréguas a favor da equidade social e da saúde, por um ambiente saudável e sustentável e pela paz ejustiça social para todos (trechos do discurso de posse de Paulo Buss, Genebra, maio de 2008). (Abrasco, 2008a: 7)

No início de 2006, por meio de sua Comissão de Epidemiologia, a Abrasco lança o professor Cesar Victora, da Universidade Federal de Pelotas (RS), candidato ao cargo de presidente da Associação Internacional de Epidemiologia (International Epidemiology Association - IEA) para o período de 2011 a 2013. Divulga o $12^{\circ}$ Congresso Mundial de Saúde Pública, que ocorreria em maio de 2009, em Istambul, e confere visibilidadee promoção ao $18^{\circ}$ Congresso Mundial de Epidemiologia e ao $7^{\circ}$ Congresso Brasileiro de Epidemiologia, em processo de organização, programados para acontecer pouco mais de um mês após a publicação do Boletim Abrasco n. 100.

Esses dois congressos de epidemiologia conjuntos foram realizados no período de 20 a 24 de setembro de 2008, em Porto Alegre (RS), e tiveram como tema "A epidemiologia na 
construção da saúde para todos: métodos para um mundo em transformação". No Boletim Abrasco n. 101, publicam-se os resultados e desdobramentos desses eventos simultâneos, que contaram com a presença de 4.837 congressistas nacionais e internacionais. Sublinha-se a eleição do professor Cesar Victora à presidência da IEA, gestão 2011-2013, destacando-se ainda a celebração dos trinta anos da Declaração de Alma-Ata (Alma-Ata, 1978) e vinte anos de nossa Constituição (1988) e da criação do Sistema Único de Saúde (SUS). Os temas dos dois congressos são estruturantes desses fóruns de debates e proposições. Na Carta de Porto Alegre, aprovada em sessão plenária de encerramento, declara-se:

Ao lado dos grandes avanços observados na sociedade brasileira no controle e erradicação de doenças, os desafios se multiplicam. Compreendem os velhos e conhecidos problemas ao lado de outros novos que invadem o cotidiano da população brasileira, como o são o alcoolismo, 0 tabagismo, as outras drogas, a violência, entre outros.

Em harmonia com o tema central do Congresso, "Epidemiologia na construção da saúde para todos: métodos para um mundo em transformação", ficou evidente para os congressistas que a efetividade de sua atuação só se concretiza na medida da urgente regulamentação da EC-29, queatribuios recursos financeiros necessários paraa sustentabilidade do nosso sistema de saúde.

(...) Refletindo sobre a atual conjuntura mundial, manifestam sua indignação frente aos recentes desdobramentos da economia globalizada que se transformou em uma ciranda financeira, utilizando inapropriadamente vultosos recursos públicos. (...)

Por fim, baseados na reunião de Ministros da Saúde da Comunidade dos Países de Língua Portuguesa realizada por ocasião dos Congressos, os epidemiologistas reconhecem que o enfrentamentodos desafios postospeloprocessosaúde-doençaimplicaaorganizaçãodeumnovo pacto. Este deve ser demarcado pela solidariedade entre povos deste e de outros continentes e pelo trabalho cooperativo internacional, como base de sustentação e de efetivação, para que se possa dar consequência ao lema de que a saúde, menos do que gasto, é condição essencial para o digno e pleno desenvolvimento das sociedades. (Abrasco, 2008b: 17)

Tambémesses doiscongressos garantiram visibilidadeà cooperação brasileira em saúde na África; à participação da Abrasco no Fórum Social Mundial Ciência e Democracia, a se realizar em Manaus, no início de 2009; e ao $12^{\circ}$ Congresso de Educação a Distância/Mercosul "Educação a distância e cidadania: um caminho para a justiça", ocorrido em outubro de 2008, no Rio de Janeiro (Abrasco, 2008b).

Tendo como objeto central a divulgação do contexto e da Declaração de Istambul ("Saúde: o primeiro direito humano"), resultante da $12^{\circ}$ Congresso Mundial de Saúde Pública, realizado em Istambul em maio de 2009, o Boletim Abrasco n. 102, de junho de 2009, torna público que:

2.380 participantes de 142 países reunidos no $12^{\circ}$ Congresso Mundial de Saúde Pública em Istambul, de 27 de abril a $1^{\circ}$ de maio de 2009, declaramos e afirmamos que:

(...) Determinantes sociais têm causado o aumento de doenças e a deterioração das condições de saúde. $O$ desemprego e a pobreza se agravam. Cerca de um bilhão de pessoas passam fome e vivem sob o temor da inanição. A segurança alimentar está ameaçada, como nunca antes 
em décadas anteriores, sobretudo na África e na Ásia. Guerras e conflitos vêm provocando mortes, desastres e miséria em muitas partes do mundo. Na semana de realização do Congresso, a eclosão de uma doença infecciosa potencialmente letal que se transformou em pandemia. A recessão econômica global, que teve início em 2008, impõe um risco ao cumprimento das Metas de Desenvolvimento do Milênio, como acordadas pelos Estados-membros das Nações Unidas no ano 2000.

Estes são tempos extremamente conturbados. (...)

Como representantes das nossas organizações, como profissionais da saúde e como cidadãos, declaramos e afirmamos os princípios e metas a seguir, comprometendo-nos a trabalhar para realizá-los.

- A saúde e o bem-estar são condições necessárias para os desenvolvimentos social, econômico e cultural nos contextos pessoal, familiar, comunitário, nacional e global.

- A saúde e o bem-estar dependem - e são inseparáveis - da assistência social e da manutenção de um mundo e uma biosfera saudáveis. (...)

- Oacesso equitativo a sistemas de saúde abrangentes, eficientesque compreendam atenção básica à saúde e serviços de saúde pública, é um direito humano. (...)

- A redução das desigualdades e disparidades de recursos econômicos entre países e pessoais, assim como dos demais recursos materiais, é pré-requisito para a melhoria da saúde pública.(...)

- A melhoria e a manutenção da saúde pública exigem compromissos profundos com e no desenvolvimento de capacidades para formação, educação e pesquisa, além da ação. (Abrasco, 2009a: 24-25)

Também nesse número do Boletim Abrasco é publicada a homenagem da $\mathrm{CPHA}$ a Paulo Buss, então presidente da WFPHA, recebida em 9 de junho de 2009, no Canadá. $O$ CPHA International Award 2009 foi conferido a ele

como reconhecimento por sua contribuição para a promoção da saúde pública em sociedades pobres, através do desenvolvimento de políticas públicas saudáveis, fortalecimento dos serviços de atenção primária, promoção dos valores da equidade no acesso a ambientes promotores da saúde e/ou do incremento da participação comunitária em saúde. (Abrasco, 2009a: 25)

Um amplo e detalhado informe, promovendo o $9^{\circ}$ Congresso Brasileiro de Saúde Coletiva ("Ciência, tecnologia e inovação na garantia do direito à saúde"), em Recife, no período de 31 de outubro a 4 de novembro de 2009, é também focado no Boletim Abrasco, n. 102:"o evento reunirá (...) todos aqueles interessados no debate, reflexão e enfrentamento dos desafios teóricos e práticos do campo" (Abrasco, 2009a: 16). Os desdobramentos desse evento e a presença oportuna e relevante do presidente Luiz Inácio Lula da Silva foram registrados nos anais do $9^{\circ}$ Congresso e no Boletim Abrasco n. 103, de dezembro de 2009.

Todos aqui sabem que a Abrasco veio fortalecendo o seu papel ao longo da década de 90, quando a maior preocupação na área da saúde era garantir as conquistas obtidas com a nova Constituição e assegurar a implementação do modelo de gestão em saúde definido pelo SUS. (Abrasco, 2009b: 3) 


\section{Desafios Abrasco nos Anos Próximos}

Em recente fórum latino-americano sobre desenvolvimento em Santiago, no Chile (Cepal, 2014a), o debate centrou-se nos novos desafios que a região enfrenta para crescer. Há que se lidar com a pobreza e as desigualdades inventando e reinventando formas de enfrentá-las. Na análise das barreiras, constata-se quea queda do custo de commodities, as altas taxas de juros e a ascensão do dólar recolocam em xeque os modelos de crescimento adotados pelos países da América Latina. Urge a busca de alternativas concentradas para a produção de matérias-primas. Oquadro defuturo dramático exigea adoção denovas estratégias de pesquisa em ciências e tecnologias em saúde, efetivamente inovadoras e integradas. É mister a definição de uma lista de prioridades conjuntas para o enfrentamento regional e nacional dessa crise contemporâneanodesenvolvimento.Asquestões relacionadasaoambiente, aoenvelhecimento populacional e à violência precisam de urgentes ações governamentais e da sociedade.

A Comissão Econômica para a América Latina e o Caribe (Cepal) oferece alternativas nos seus três documentos bianuais sobre desenvolvimento nesta região, desenvolvidos respectivamente em 2010, 2012 e 2014, para apoiar as opções dos governos locais (Cepal, 2010, 2012, 2014b). Teóricos e críticos do desenvolvimento descrevem expectativas e proposições. Países formulam seus planos nacionais de desenvolvimento. A sociedade civil procura-edeve-participarativamente. Aquise inseremos desafios das associações nacionais de saúde pública, caso da Abrasco e de outras entidades.

Dadas as reconhecidas conexões entre desenvolvimento e saúde, reafirmadas no documento "O futuro que queremos" (United Nations, 2012), resultante da Conferência das Nações Unidas sobre Desenvolvimento Sustentável, cabe de forma inequívoca um papel muito importanteàsassociaçõesnacionais desaúdepúblicanoavançodos processosglobalenacionais de um desenvolvimento integral e equitativo, diferente do mero crescimento econômico como se conhece até aqui, no mais das vezes inequitativo, excludente e ecoagressivo.

Reunir evidências relacionadas aos efeitos da crise econômica mundial - gerada a partir de 2007 nos países centrais do capitalismo global - sobre a saúde e a qualidade de vida (Stuckler \& Basu, 2013) e transformá-las em matéria política a ser debatida pela sociedade civil, servindo de alerta a governos populares, devem ser o objetivo central de associações nacionais comprometidas com a saúde da população.

É necessário estimular conexões e mesmo alianças formais entre organizações da sociedade civil envolvidas no mesmo ideário. A ação em conjunto com o parlamento, reforçando a democracia representativa na busca de compromissos em prol da saúde e da qualidade de vida, é a esperada para associações como a Abrasco.

O que se deseja - e claramente é apontado pelos movimentos políticos da instituição é que a Abrasco busque na sua história de 35 anos a inspiração - e na análise política sistemática da realidade a orientação - para suas ações futuras. 


\section{REFERÊNCIAS}

ASSOCIAÇÃO BRASILEIRA DE SAÚDE COLETIVA (ABRASCO). II Congresso Brasileiro de Saúde Coletiva e ll Congresso Paulista de Saúde Pública. Boletim da Associação Brasileira de Pós-Graduaçã̃o em Saúde Coletiva, 31, out.-dez. 1988.

ASSOCIAÇÃO BRASILEIRA DE SAÚDE COLETIVA (ABRASCO). Carta de São Paulo. Boletim da Associação Brasileira de Pós-Graduação em Saúde Coletiva, 34, jun.-jul. 1989.

ASSOCIAÇÃO BRASILEIRA DE SAÚDE COLETIVA (ABRASCO). Carta de Porto Alegre e de Belo Horizonte - A Saúde como Direito à Vida. Boletim da Associação Brasileira de Pós-Graduação em Saúde Coletiva, 46: 1-2, abr.-jun. 1992a.

ASSOCIAÇÃO BRASILEIRA DE SAÚDE COLETIVA (ABRASCO). I Congresso Iberoamericano de Epidemiologia e VII Jornadas de Salud Pública y Administración Sanitária. Boletim da Associação Brasileira de Pós-Graduação em Saúde Coletiva, 46, abr.-jun. 1992b.

ASSOCIAÇÃO BRASILEIRA DE SAÚDE COLETIVA (ABRASCO). Saúde: o feito por fazer. Boletim da Associação Brasileira de Pós-Graduação em Saúde Coletiva, 51: 1, out.-dez. 1993.

ASSOCIAÇÃO BRASILEIRA DE SAÚDE COLETIVA (ABRASCO). Editorial. Boletim da Associação Brasileira de Pós-Graduação em Saúde Coletiva, 88: 2-3, maio-set. 2003.

ASSOCIAÇÃO BRASILEIRA DE SAÚDE COLETIVA (ABRASCO). Editorial. Boletim da Associação Brasileira de Pós-Graduação em Saúde Coletiva, 90, ano XXI: 2-3, maio 2004.

ASSOCIAÇÃO BRASILEIRA DE SAÚDE COLETIVA (ABRASCO). Saúde coletiva em um mundo globalizado: por uma agenda solidária. Editorial. Boletim da Associação Brasileira de Pós-Graduação em Saúde Coletiva, 97: 2, out. 2006a.

ASSOCIAÇÃO BRASILEIRA DE SAÚDE COLETIVA (ABRASCO). Reafirmando a luta por um mundo melhor. Boletim da Associação Brasileira de Pós-Graduação em Saúde Coletiva, 97: 5, out. 2006b.

ASSOCIAÇÃO BRASILEIRA DE SAÚDE COLETIVA (ABRASCO). Declaração do Rio - Abrascão: compromissos renovados, a agenda continua! Boletim da Associação Brasileira de Pós-Graduação em Saúde Coletiva, 97: 10-12, out. 2006c.

ASSOCIAÇÃO BRASILEIRA DE SAÚDE COLETIVA (ABRASCO). Aproximando a academia e os movimentos sociais: a luta pelo reconhecimento da saúde como direito. Boletim da Associação Brasileira de Pós-Graduação em Saúde Coletiva, edição especial: 28-31, set. 2007.

ASSOCIAÇÃO BRASILEIRA DE SAÚDE COLETIVA (ABRASCO). Sanitarista brasileiro assume Presidência da Federação Mundial de Saúde Pública. Boletim da Associação Brasileira de Pós-Graduação em Saúde Coletiva, 100: 6-7, 16, ago. 2008a.

ASSOCIAÇÃO BRASILEIRA DE SAÚDE COLETIVA (ABRASCO). Carta de Porto Alegre. Boletim da Associação Brasileira de Pós-Graduação em Saúde Coletiva, 101: 3, 8-9, 17, 21-22, 24, dez. 2008b.

ASSOCIAÇÃO BRASILEIRA DE SAÚDE COLETIVA (ABRASCO). Saúde: o primeiro direito humano da Declaração de Istambul. Boletim da Associação Brasileira de Pós-Graduação em Saúde Coletiva, 102: 16-17, jul. 2009a.

ASSOCIAÇÃO BRASILEIRA DE SAÚDE COLETIVA (ABRASCO). Editorial. Boletim da Associação Brasileira de Pós-Graduação em Saúde Coletiva, 103: 2-3, dez. 2009b.

BUSS, P. et al. Desenvolvimento sustentável e governança em saúde global. Reciis - Revista Eletrônica de Comunicação, Informação \& Inovação em Saúde, 6(3): 1-10, 2012. Disponível em: <www.reciis.cict.fiocruz. br/index.php/reciis/article/view/636>. Acesso em: 9 fev. 2015. 
CADERNOS DE SAÚDE PÚBLICA. Declaração final do $1^{\circ}$ Congresso Brasileiro de Saúde Coletiva. Cadernos de Saúde Pública, 2(3): 382-384, 1986. Disponível em: <www.scielo.br/scielo.php?pid=S0102311X1986000300013\&script=sci_arttext>. Acesso em: 6 dez. 2014.

CANADIAN PUBLIC HEALTH ASSOCIATION (CPHA). Strengthening of Public Health Associations Program (Sopha), 1985. Disponível em:<www.cpha.ca/en/programs/sopha.aspx>. Acesso em: 9 fev. 2015.

COMISSÃO ECONÔMICA PARA A AMÉRICA LATINA E O CARIBE (CEPAL). La hora de la igualdad, 2010. Disponível em: <http://repositorio.cepal.org/bitstream/handle/11362/13309/S2010986_ es.pdf? sequence=1>. Acesso em: 6 dez. 2014.

COMISSÃO ECONÔMICA PARA A AMÉRICA LATINA E O CARIBE (CEPAL). Cambio estructural para equidad: una visión integrada del desarrollo, 2012. Disponível em: $<$ www.cepal.org/pses34/noticias/ documentosdetrabajo/4/47424/2012-SES-34-Cambio_estructural.pdf >. Acesso em: 6 dez. 2014.

COMISSÃO ECONÔMICA PARA A AMÉRICA LATINA E O CARIBE (CEPAL). Pactos para la igualdad: hacia un futuro sostenible, 2014a. Disponível em: $<$ www.cepal.org/es/publicaciones/pactospara-la-igualdad-hacia-un-futuro-sostenible-trigesimo-quinto-periodo-de >. Acesso em: 6 dez. 2014.

COMISSÃO ECONÔMICA PARA A AMÉRICA LATINA E O CARIBE (CEPAL). Panorama Social da América Latina - 2013. Santiago de Chile: Cepal, 2014b.

FIDLER, D. The Challenges of Global Health Governance. New York: Council on Foreign Relations, 2010. Disponível em: <http://ec.europa.eu/health/eu_world/docs/ev_20111111_rd01_en.pdf >. Acesso em: 9 fev. 2015.

HOBSBAWM, E. Era dos Extremos: o breve século XX 1914-1991. Trad. Marcos Santa Rita. Rio de Janeiro: Companhia das Letras, 1994.

KICKBUSCH, I.; SILBERSCHMIDT, G. \& BUSS, P. Global health diplomacy: the need for new perspectives, strategic approaches and skills in global health. Bulletin ofWorld Health Organization, 85:230232, 2007. Disponível em:<www.who.int/bulletin/volumes/85/3/06-039222/en/>. Acesso em: 9 fev. 2015.

ORGANIZAÇÃO DAS NAÇÕES UNIDAS (ONU). Objetivos de Desenvolvimento do Milênio, 2000. Disponível em: <www.un.org/millenniumgoals >. Acesso em: 9 fev. 2015.

ORGANIZAÇÃO DAS NAÇÕES UNIDAS (ONU). Departamento de Assuntos Econômicos e Sociais. Agenda do Desenvolvimento pós-2015, 2013. Disponível em: <www.un.org/es/development/desa/ development-beyond-2015.html>. Acesso em: 9 fev. 2015.

ORGANIZAÇÃO DAS NAÇÕES UNIDAS (ONU). Objetivos do Desenvolvimento Sustentável (ODS), 2014. Disponível em: <https://sustainabledevelopment.un.org/sdgsproposal>. Acesso em: 9 fev. 2015.

STUCKLER, D. \& BASU, S. The Body Economic: why austerity kills. 1. ed. London: Basic Books, 2013.

THAKUR, R. \& WEISS, T. G. The UN and Global Governance: an idea and its prospects. Indiana: Indiana University Press, 2007.

UNITED NATIONS. The future we want, 2012. Disponível em: <www.un.org/ga/search/view_doc. asp?symbol=A/RES/66/288\&Lang $>$. Acesso em: 6 dez. 2014. 